\title{
Predicting Future Business Leaders Participation in Continuing Education
}

\author{
Charles Ericksen \\ University of Montana Western, United States
}

\begin{abstract}
This paper discusses the attitudes toward and perceived barriers to participating in adult and continuing education by undergraduate business students, graduate business students, and small business managers. Data was gathered about these populations with the Adult Attitudes Toward Continuing Education Scale (AACES), the Deterrents to Participation Scale-General (DPS-G), and a demographic sheet. Findings suggest that female undergraduate business students, graduate business students, and small business managers in Montana hold more favorable attitudes toward adult and continuing education than males. In addition, it was determined that female undergraduate business students in Montana perceived significantly more deterrents and barriers to participation in adult and continuing educational activities than males. Finally, it was determined that small business managers in Nebraska and Montana along with graduate business students in Nebraska who had participated in adult and continuing education had more favorable attitudes than nonparticipants toward these educational activities.
\end{abstract}

\section{Introduction}

The issue of participation has held a long-standing position of prominence in adult education research. In fact, this is one of the few areas where adult education researchers have begun to build a systematic knowledge base [1]. This dominance in research and investigation helped determine that certain characteristics emerge that distinguish participants from nonparticipants. In particular, Johnstone and Rivera [2] pointed out that these two groups differed in age, amount of formal schooling, and where they lived. More recently, Ericksen [3] found in Montana that business managers who participated in adult and continuing education tend to be older, better educated, have more business experience, and earn significantly more income.
In the seminal research on participation, Houle [4] developed a typology of orientations for participation in adult education activities. This typology has provided a theoretical basis for much of the research on reasons for participation in adult educational activities. Houle's major objective was not so much to investigate motivation as it was to examine why these learners were so active. Out of this study, three subgroups of learners emerged which were categorized as goaloriented, activity-oriented, and learning-oriented. Goal-oriented learners were people who saw learning as "a series of episodes, each beginning with the identification of a need or an interest" [7]. On the other hand, activity-oriented learners were participating "primarily for the sake of activity itself rather than to develop a skill or learn subject matter" [7]. Finally, those identified as learning-oriented participated in activities primarily for the sheer joy of learning.

Building on Houle's study, Boshier [5] identified numerous clusters of reasons for participation in adult education that not only lent support to Houle's earlier study but also showed that motives for participation may be more complex that Houle originally believed. Boshier [5] found that participants were predominantly growth or deficiency motivated. It was determined that a vast majority of the population was deficiency oriented and that they were seeking an equilibrium or homeostasis. In contrast, the growth-oriented person was seeking nonequilibrium or heterostasis. Boshier [5] concluded that what impels motivation for participation is more complex than Houle had originally believed and that adults participate in adult education for a plethora of reasons. Because of this complexity, he suggested that researchers take a holistic approach when studying adult learners and their motives for participation.

Numerous studies have been conducted in adult education that are germane to participation in learning activities [6]. However, while it is valuable to know why adults do participate, it is equally as critical to 
know why they do not participate in learning activities. The situation can be viewed as a two-sided coin with reason for participation on one side and barriers to participation on the other. Cross [7] classified barriers to learning under three major headings: situational, institutional, and dispositional barriers (p. 98).

Situational barriers arise from one's situation in life at a given time (p. 98). Upon closer examination of these barriers, it appears that they primarily relate to the finite amount of resources possessed by an individual. Cost, not enough time, home responsibilities, and job responsibilities are examples of barriers included in this category. Over time, many of these situational barriers may become nonexistent and disappear as barriers. It is common for families to have more money, free time, and less childcare responsibility as the family matures. However, as some of these barriers disappear, other barriers may take their place (e.g. health).

Institutional barriers consist of all those practices and procedures that exclude or discourage adults from participating in educational activities (p. 98). Examples in this category consist of inconvenient class schedules or locations, amount of time required to complete a program, and lack of information on course offerings. One reason these barriers exist may be because institutions were originally devised for a specific group other than the adult education student. For example, college and universities were devised to accommodate full-time day students and not to serve part-time day or night learners.

Dispositional barriers are the third type of barriers. These barriers primarily relate to the self-perception and attitude of the learner. Being afraid that one is too old to learn, having low academic confidence, not enjoying studying, and being tired of school are examples of dispositional barriers (p. 98). Subsequent research [3] [8] [9] [10] [11] [12] [13] [14] has focused additional attention on the deterrents to participation in adult education. In part, these studies identified clusters of reasons for nonparticipation by various groups. Like Houle's original typology, these may prove valuable in understanding the total pattern of motivational factors that influence an adult's participation in adult educational activities.

Participation in adult education activities may also be influenced by an adult's attitude toward adult education. An attitude is a "learned tendency to react in a consistently favorable or unfavorable manner toward people, objects, ideas, or situations" [15]. Although practitioners suggest that attitudes influence an adult's participation in adult education, a paucity of research exists on the relationship of participation to attitudes toward adult and continuing education. Yet, those limited studies that have been conducted suggest that attitudes are related to participation in adult education [16]. In a 1970 study, it was found that favorable attitudes toward adult education enhanced participation by various groups in adult educational activities [17]. Two decades later, it was determined, that one's attitude toward adult education was the most important factor in the discrimination of participants and nonparticipants in adult and continuing education [10]. More recently, it was found that small business managers in Montana who have participated in adult and continuing education have more favorable attitudes toward adult and continuing education than nonparticipants [3].

The aforementioned suggests that attitudes toward and perceived barriers to adult and continuing education have an impact on participation. Therefore, the purpose of this study was to investigate perceived barriers to participation in adult and continuing education and attitudes toward adult and continuing education by undergraduate business students. This group's attitude toward adult and continuing education and their perceived barriers toward participating in adult and continuing education may shed light on their future participation in these educational activities.

\section{Graduate Students Attitudes Toward Continuing Education}

At the University of Nebraska at Kearney (UNK), Ericksen examined graduate business student's attitudes toward continuing education [18]. Data for this study were gathered from a population of graduate students enrolled in the Master of Business Administration degree program. Population data was collected at random from 100 students. Usable data packets were received from 52 individuals for a response rate of 52\%. The Adult Attitudes Toward Continuing Education Scale (AACES) was used to obtain this data. This scale was developed by Darkenwald and Hayes [8] to identify attitudes toward adult and continuing education. The AACES is a 22item instrument, which employs a five-point Likert scale to provide a measure of adult attitudes toward continuing education. Along with the AACES, some of the information collected was demographic which was used to construct a profile of graduate business students at UNK. The data which was collected with the AACES and demographic sheet were organized to facilitate analysis. The analysis included an examination of participants and nonparticipants in continuing education, along with participation by gender.

Participants in this study had an average age of 37 years. The respondents' ages ranged from 22 years to 55 years. Of this group, $62 \%$ were males and $38 \%$ were females. Respondents' business experience ranged from 3 years to 32 years with an average of 14 


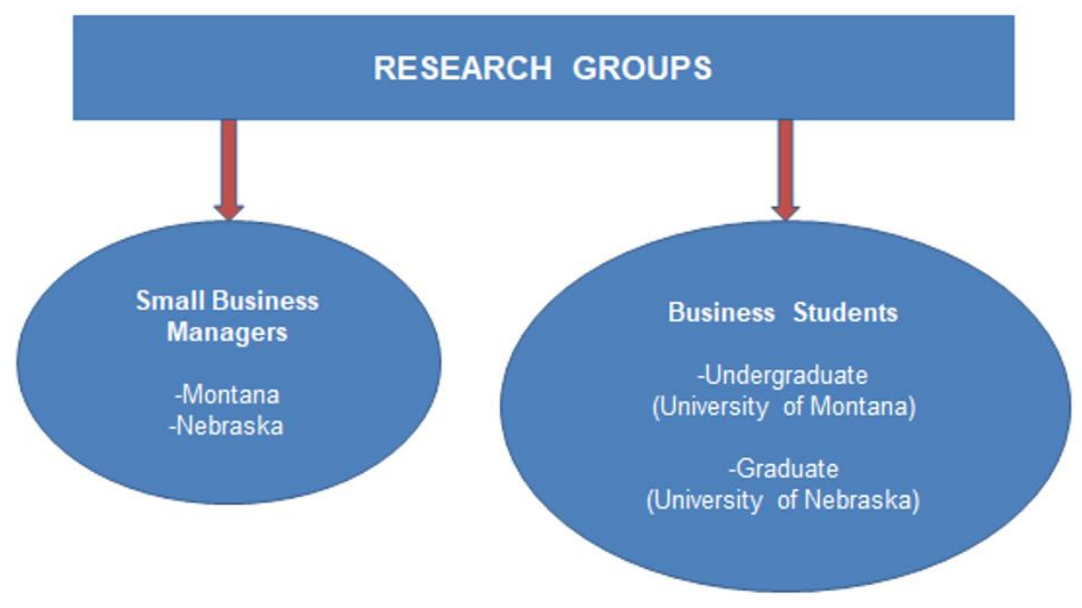

Figure 1. The research groups used in survey data [3] [10] [18] [19]

years. This group had participated in continuing educational activities; the participation status of respondents revealed that $73 \%$ had participated while $27 \%$ had not participated. Of this group $63 \%$ were from the state of Nebraska, $31 \%$ were from other parts of the United States, and 6\% were from foreign countries. The group varied in its attitude toward continuing education. On the AACES, which has a possible range of 22 to 110 , the groups' average was 92.9; their scores ranged from 79 to 110 . Those who had participated in continuing education scored 94.7 while nonparticipants scored 88.0 on the AACES. Finally, males scored 91.8 and females scored 94.6. A t-test was utilized in this study with significance for two-tailed tests set at .05 .

Utilizing the aforementioned statistical approach, it was determined that no significant difference existed between the attitudes of male and female graduate business students at UNK. However, a statistically significant difference was found between the attitudes of those graduate business students who participate and those who do not participate in adult and continuing educational activities.

\section{Business Managers Attitudes Toward and Perceived Barriers to Participating in Continuing Education}

A 1989 study investigated the participation of small business managers in adult and continuing educational activities in Nebraska [10]. The population for this study was small business managers who were members of the Nebraska State Chamber of Commerce (NSCOC). The 1988 membership of the NSCOC consisted of a wide range of diverse members. The small business managers selected for participation in this study resided in varied geographical locations in the state, possessed various income levels, had varied educational backgrounds, had differing amounts of business experience, represented both genders, and were a wide variety of age. A random sample of 600 small business manages was obtained from the 1989 membership roster. A total of 302 usable surveys were returned for a response rate of $50.3 \%$. The data were collected with the Adult Attitudes toward Continuing Education Scale (AACES), the Deterrents to Participation Scale-General (DPS-G), and a demographic sheet. The data were organized to facilitate statistical analysis. Discriminant analysis was done using select demographics along with the total score on the AACES and the DPS-G.

The study respondents had an average age of 48.1 years. The educational level of respondents ranged from nine to 18 years with an average of 15.2 years. Their income average was \$73,573. Respondents' years in business ranged from one year to 65 years with an average of 22.3 years. This group had participated in adult educational activities; the participation status of respondents revealed that $67 \%$ had participated while $33 \%$ had not participated.

The group varied in its perceived barriers to participation and its attitude towards adult and continuing education. On the DPS-G, which had a possible range of 34 to 170 , the group's average score was 73.6 and their scores ranged from 34 to 135 . On the AACES, which had a possible range of 22 to 110 , the group's average was 88.3 and their scores ranged from 29 to 110 .

An analysis of the group means for the various variables indicated that participants and nonparticipants did not differ greatly on most of the variables. On most of the variables, the participant group scored higher than the nonparticipant group. On the AACES, adult education participants scored an 
average of 90.2 and nonparticipants scored 84.5. On the DPS-G, participants scored an average of 72.4 and nonparticipants 73.1. The average age of participants was 48 years and nonparticipants were 46 years. Participants had an average educational level of 15.3 years and nonparticipants had 14.9 years. The average gross income of participants was $\$ 76,251$ and nonparticipant's gross income was $\$ 68,680$. Finally, participants had an average of 22.8 years' experience and nonparticipants had 20.3 years. The participants group was consistently higher on these variables with the DPS-G total score the only minor exception.

In conclusion, the Nebraska study found that attitudes toward adult education were the most powerful discriminators of adult education participation. In addition, participants tend to be older, better educated, have more business experience, and earn a greater income.

Ericksen [3] used the AACES and DPS-G along with select demographics to examine small business manager's participation in adult and continuing education in Montana. In this study, the population examined was small business managers who were members of the Montana State Chamber of Commerce (MSCOC).

The 2013 membership of the MSCOC consisted of a wide range of diverse members. The small business managers selected for participation resided in varied geographical locations in the state, possessed various income levels, had diverse educational backgrounds, had differing amounts of business experience, represented both genders, and were a wide range of age. From the population of approximately 1200 a random sample of 200 small business managers was obtained from the 2013 membership roster. Forty-one usable surveys were returned for a response rate of $20.5 \%$. The data were collected with the Adult Attitudes Toward Continuing Education Scale (AACES), the Deterrents to Participation Scale-General (DPS-G), and a demographic sheet. The data were organized to facilitate statistical analysis. A t-test was utilized to assess whether a statistically significant difference existed between the participants and nonparticipants in continuing education.

The study respondents had an average age of 52.2 years. Their ages ranged from 24 years to 80 years. Of this group, $45 \%$ were males and $55 \%$ were females. The educational level of respondents ranged from nine to 20 years with an average of 15.4 years. Their gross income ranged from $\$ 20,000$ to $\$ 300,000$ with an average of $\$ 116,444$. Respondent's years in business extended from four years to 47 years with an average of 22.7 years. This group had participated in adult educational activities; the participation status of respondents revealed that $61 \%$ had participated while $39 \%$ had not participated.
The group varied in its perceived barriers to participation and its attitude towards adult and continuing education. On the DPS-G, which had a possible range of 34 to 170 , the group's average score was 70.79 and their scores ranged from 34 to 130 . On the AACES, which had a possible range of 22 to 110 , the group's average was 88.13 and their scores ranged from 56 to 110 .

An analysis of the group means for the various variables indicated that participants and nonparticipants did not differ greatly on most of the variables. On all the variables, the participant group scored higher than the nonparticipant group. On the AACES, adult education participants scored an average of 91.42 and the nonparticipants scored 82.92. On the DPS-G, participants scored an average of 71.78 and nonparticipants 69.67. The average age of participants was 53 years and nonparticipants were 50 years. Participants had an average educational level of 15.68 years and nonparticipants had 15.08 years. The average gross income of participants was $\$ 130,278$ and nonparticipants was $\$ 88,778$. Finally, participants had an average of 23.6 years of business experience and nonparticipants had 21.42. Although the participant group was consistently higher on these variables, the AACES total score and gross income were the only variables with sizeable mean differences between the groups. This difference was statistically significant at the .05 level on both the AACES total score and the gross income levels of small business participants and nonparticipants in adult and continuing education in Montana.

In the Montana study, it was determined that small business managers who had participated in adult and continuing education had more favorable attitudes toward adult and continuing education than nonparticipants. In addition, they tended to be older, better educated, have more business experience, and earn significantly more income.

\section{Undergraduates Attitudes Toward and Perceived Barriers to Participating in Continuing Education}

The population for this study was undergraduate business students enrolled at the University of Montana Western and Montana Tech of the University of Montana. From this population, 96 students were randomly selected for study. Two instruments made data identification and collection possible; they were the Adult Attitudes Toward Continuing Education Scale (AACES) and the Deterrents to Participation Scale for the General Population (DPS-G). The Adult Attitude Toward Continuing Education Scale is a 22-item, five-point Likert scale with a possible score range of 22 to 110 which identifies attitudes toward continuing education 
[8]. The Deterrents to Participation Scale - General (DPS-G) is a 34-item, five-point Likert scale with a possible score range of 34 to 170 which provides a measure of perceived deterrents to participation in adult education by the general public [9]. Both aforementioned instruments have been used in numerous environments with various populations and they were found to be valid and reliable with these groups [10] [11] [12] [13] [14] [3]. In addition, the data collected with the AACES and the DPS-G was organized to facilitate statistical analysis. A t-test was utilized to assess whether a statistically significant difference existed between male and female undergraduate business students' attitudes toward adult and continuing education and their perceived barriers toward participating in adult and continuing education.

Undergraduate business students' attitudes toward continuing education were examined at Montana Tech of the University of Montana during the 2014-2015 academic year. An accounting class of 30 students was selected for study in the fall of 2014 and a legal environment of business class of 46 students was examined in the spring of 2015. The 2014 class had an average score of 86.0 on the AACES and the 2015 class had an average of 87.3. This difference between the 2014 and 2015 classes was not statistically significant. Male students in the 2014 class had an average on the AACES of 85.1 and females scored 88.9. Male students in the 2015 class scored 85.6 and females scored 89.5. In both classes, females scored higher on the AACES than males. However, this difference was not statistically significant.

The 2015 spring legal environment in business class from Montana Tech of the University of Montana was also utilized along with a 2017 fall class of 20 undergraduate accounting students from the University of Montana Western to examine perceived deterrents

Table 1. Adult Attitudes Toward Continuing Education Scale (AACES) [3] [10] [18] [19]

\begin{tabular}{|l|c|c|c|c|c|c|}
\hline \multirow{2}{*}{ AACES } & Location & Mean & Male & Female & Participants & Participants \\
\hline 1989 & Small Business Nebraska & 88.3 & NA & NA & 90.2 & $84.5^{\star}$ \\
\hline 2014 & Small Business Montana & 88.1 & 87.6 & 88.7 & 91.4 & $82.9^{\star}$ \\
\hline 1991 & $\begin{array}{c}\text { University of Nebraska at } \\
\text { Kearney Graduate Students }\end{array}$ & 92.9 & 91.8 & 94.6 & 94.7 & $88.0^{*}$ \\
\hline 2014 & $\begin{array}{l}\text { Montana Tech of University } \\
\text { of Montana Undergraduate }\end{array}$ & 86.0 & 85.1 & 88.9 & NA & NA \\
\hline 2015 & $\begin{array}{l}\text { Montana Tech of University } \\
\text { of Montana Undergraduate }\end{array}$ & 87.3 & 85.6 & 89.5 & NA & NA \\
\hline \multicolumn{2}{|l|}{ Asterisk (*) denotes significant values. } \\
\hline
\end{tabular}

Table 2. Deterrents to Participation Scale-General (DPS-G) [3] [10] [18] [19]

\begin{tabular}{|c|c|c|c|c|c|c|}
\hline DPS-G & Location & Mean & Male & Female & Participants & Non-Participants \\
\hline 1989 & Small Business Nebraska & 73.6 & NA & NA & 72.4 & 73.1 \\
\hline 2014 & Small Business Montana & 71.0 & 74.4 & 67.6 & 71.8 & 69.7 \\
\hline 2015 & $\begin{array}{c}\text { Montana Tech of University of } \\
\text { Montana Undergraduate }\end{array}$ & 82.2 & 73.6 & $90.3^{*}$ & NA & NA \\
\hline 2017 & $\begin{array}{c}\text { University of Montana Western } \\
\text { Undergraduate }\end{array}$ & 81.9 & 71.0 & $86.5^{*}$ & NA & NA \\
\hline Statistically significant items have an asterisk (*).
\end{tabular}


toward participating in continuing education. This analysis was done with the DPS-G. The 2015 class had an average score of 82.2 and the 2017 class had an average of 81.9. Male students in the 2015 study scored an average of 73.6 and females scored an average of 90.3 on the DPS-G. This difference between genders in the 2015 was statistically significant at the .05 level. In addition, male students in the 2017 study had an average score on the DPS-G of 71.0 and females scored 86.5. This difference was also found to be statistically significant. Females scored higher on all 34-items on the DPS-G at both campus locations. On the DPS-G, five individual questions were found to be statistically significant between genders. These questions were that I could not attend regularly (\#16), it would take time away from my family (\#23), I could not afford travel, books, etc. (\#25), trouble with childcare (\#28), and course offered in an unsafe area (\#31).

\section{Conclusion}

Female undergraduate business students, female graduate business students, and female small business managers in Montana all scored higher on the AACES than males. Therefore, it appears that females have more favorable attitudes toward adult and continuing education than males in many different environments. In addition, small business managers in Nebraska, small business managers in Montana, along with graduate business students at UNK who have participated in adult and continuing educational activities scored higher on the AACES than nonparticipants. This difference between participants and nonparticipants was found to be statistically significant.

Female undergraduate business students at both University of Montana locations scored higher than males on all 34-items on DPS-G scale. This difference between genders was statistically significant at the 0.05 level. The aforementioned suggests that females perceive more barriers and deterrents to participation in adult and continuing education than males do at Montana Tech of the University of Montana and the University of Montana Western. It should be noted that these same female undergraduate business students who perceived more barriers and deterrents to participating in adult and continuing education also had more favorable attitudes toward adult and continuing education than males did at both University of Montana campuses.

In conclusion, research findings found that participants had more favorable attitudes toward adult and continuing education than nonparticipants, that females generally have more positive attitudes toward adult and continuing education than males, and that female undergraduate business students perceived substantially more barriers and deterrents to participation in adult and continuing education than male business undergraduate students. Finally, it should be noted that male small business managers in Montana perceived more barriers to participation in adult and continuing education than female small business managers did. However, this difference between male and female small business managers perceived barriers to participation in adult and continuing education in Montana was not statistically significant.

\section{Acknowledgements}

I would like thank Ms. Amy Kathleen Ericksen for her generous support, guidance, patience, insight, and academic skill for the completion of this project. Without her guiding hand this project would not have been possible.

\section{References}

[1] Darkenwald, G. G. and Merriam, S. (1982) Adult Education: Foundations of Practice, Harper \& Row, New York.

[2] Johnstone, J. W. C. and Rivera, R. J. (1965) Volunteers for Learning, Aldine Publishing, Chicago.

[3] Ericksen, C. (2015) 'Small Business Attitudes Toward and Perceived Barriers to Participating in Adult Educational Activities in Montana', Proceedings of the 13th Annual International Conference on Education, pp. 384.

[4] Houle, C. O. (1961) The Inquiring Mind, University of Wisconsin Press, Madison.

[5] Boshier, R. (1971) 'Motivational Orientations of Adult Educational Participants: A Factor Analytic Exploration of Houle's Typology', Adult Education 17 (3), pp. 152-156.

[6] Burgess, P. (1971) 'Reasons for Adult Participation in Group Educational Activities', Adult Education 22 (1), pp. 329.

[7] Cross, K. P. (1981) Adults as Learners, Jossey-Bass, San Francisco.

[8] Darkenwald, G. G. and Hayes, E. (1988) 'Assessment of Adult Attitudes Toward Continuing Education', International Journal of Lifelong Education 7, pp. 197-204.

[9] Darkenwald, G.G. and Valentine, T. (1985) 'Factor Structure of Deterrents to Public Participation in Adult Education', Adult Education Quarterly 35 (4), pp. 177-189.

[10] Ericksen, C. (1990) 'Influence of Barriers to Participation and Attitudes Toward Adult Education on Small 
Business Managers' Participation in Adult Education', Unpublished doctoral dissertation, Montana State University, Bozeman.

[11] Reed, N. L., (1994). 'Perceived Deterrents to Classified Staff's Voluntary Participation in Staff Development Activities', Unpublished doctoral dissertation, Colorado State University, Fort Collins.

[12] Hughes, B. J. (2005). 'Identifying Attitudes and Deterring Factors Toward Continuing Education Among Certified Athletic Trainers', The Internet Journal of Allied Health Sciences and Practice 3 (1), pp. 1-12.

[13] Eggleston, M. A. (2007) 'Participation and NonParticipation in Formal Adult Education: A Study of Deterrents for an Organizational Leadership Development Program', Unpublished doctoral dissertation, Virginia Polytechnic Institute and State University, Falls Church.

[14] Selman, J. T. (2013) 'Barriers to Participation in Religious Adult Education: An Exploratory Study', Unpublished doctoral dissertation, Kansas State University, Manhattan.

[15] Siegel, G. and Ramanauskas-Marconi, H. (1989) Behavioral Accounting, Southwestern, Cincinnati.

[16] Adolph, T. and Whaley, R. F. (1967) 'Attitudes toward Adult Education’, Adult Education 17 (3), pp. 152-156.

[17] Seaman, D. F. and Schroeder, W. L. (1970) 'The Relationship between Extent of Educative Behavior by Adults and Their Attitudes toward Continuing Education', Adult Education Journal 20 (2), pp. 99-105.

[18] Ericksen, C. (1991) 'Future business leader's attitudes toward continuing education', Paper Presented at the American Association for Adult and Continuing Education Conference, Montreal.

[19] Ericksen, C. (2017) 'Business Student's Attitudes Toward and Perceived Deterrents to Participating in Continuing Education', Paper presented at the London International Conference on Education, Cambridge, United Kingdom. 